\title{
From SARS-CoV-2 hematogenous spreading to endothelial dysfunction: clinical- histopathological study of cutaneous signs of COVID-19
}

Angela Patri ${ }^{1 * \dagger}$, Maria Vargas ${ }^{2 \dagger}$, Pasquale Buonanno ${ }^{2}$, Maria Carmela Annunziata ${ }^{1}$, Daniela Russo ${ }^{3 *}$, Stefania Staibano ${ }^{3 \dagger}$, Giuseppe Servillo ${ }^{2 \dagger}$ and Gabriella Fabbrocini ${ }^{1 \dagger}$

\begin{abstract}
Background: To date, very few studies on clinical-histopathological correlations of cutaneous disorders associated with COVID-19 have been conducted.

Case presentation: The Case 1 was a 90-year-old man, who tested positive for SARS-CoV-2 from a nasopharyngeal swab. Two days later, he was hospitalized and after eleven days transferred to Intensive Care Unit. A chest CT showed bilateral ground-glass opacities. Just that day, an erythematous maculo-papular rash appeared on trunk, shoulders and neck, becoming purpuric after few days. Histological evaluations revealed a chronic superficial dermatitis with purpuric aspects. The superficial and papillary dermis appeared edematous, with a perivascular lympho-granulocytic infiltrate and erythrocytic extravasation. At intraepithelial level, spongiosis and a granulocyte infiltrate were detected. Arterioles, capillaries and post-capillary venules showed endothelial swelling and appeared ectatic. The patient was treated with hydroxychloroquine, azithromycin, lopinavir-ritonavir and tocilizumab.

Regrettably, due to severe lung impairment, he died.

The Case 2 was a 85-year-old man, admitted to Intensive Care Unit, where he was intubated. He had tested positive for SARS-CoV-2 from a nasopharyngeal swab two days before. A chest RX showed bilateral atypical pneumonia. After seven days, a cutaneous reddening involving trunk, upper limbs, neck and face developed, configuring a suberythroderma. Histological evaluations displayed edema in the papillary and superficial reticular dermis, and a perivascular lymphocytic infiltrate in the superficial dermis. The patient was treated with hydroxychloroquine, azithromycin, lopinavir-ritonavir and tocilizumab. Sub-erythroderma as well as respiratory symptoms gradually improved until healing.

(Continued on next page)
\end{abstract}

\footnotetext{
*Correspondence: patriangela.ap@gmail.com; danielarusso83@yahoo.it

${ }^{\dagger}$ Angela Patri and Maria Vargas equally contributed to this work.

${ }^{\dagger}$ Stefania Staibano, Giuseppe Servillo, and Gabriella Fabbrocini equally contributed to this work.

'Department of Clinical Medicine and Surgery, Section of Dermatology and Venereology, University of Naples Federico II, Via Pansini 5, Napoli, Italy

${ }^{3}$ Department of Advanced Biomedical Sciences, Pathology Section, University of Naples Federico II, via Pansini 5, Naples, Italy

Full list of author information is available at the end of the article
}

(C) The Author(s). 2021 Open Access This article is licensed under a Creative Commons Attribution 4.0 International License, which permits use, sharing, adaptation, distribution and reproduction in any medium or format, as long as you give appropriate credit to the original author(s) and the source, provide a link to the Creative Commons licence, and indicate if changes were made. The images or other third party material in this article are included in the article's Creative Commons licence, unless indicated otherwise in a credit line to the material. If material is not included in the article's Creative Commons licence and your intended use is not permitted by statutory regulation or exceeds the permitted use, you will need to obtain permission directly from the copyright holder. To view a copy of this licence, visit http://creativecommons.org/licenses/by/4.0/ The Creative Commons Public Domain Dedication waiver (http://creativecommons.org/publicdomain/zero/1.0/) applies to the data made available in this article, unless otherwise stated in a credit line to the data. 
(Continued from previous page)

Conclusions: The endothelial swelling detected in the Case 1 could be a morphological expression of SARS-CoV-2induced endothelial dysfunction. We hypothesize that cutaneous damage could be initiated by endothelial dysfunction, caused by SARS-CoV-2 infection of endothelial cells or induced by immune system activation. The disruption of endothelial integrity could enhance microvascular permeability, extravasation of inflammatory cells and cytokines, with cutaneous injury. The Case 2 developed a sub-erythroderma associated with COVID-19, and a non-specific chronic dermatitis was detected at histological level. We speculate that a purpuric rash could represent the cutaneous sign of a more severe coagulopathy, as highlighted histologically by vascular abnormalities, while a sub-erythroderma could be expression of viral hematogenous spreading, inducing a non-specific chronic dermatitis.

Keywords: Histopathology, Skin, COVID-19, Case report, Endothelial swelling

\section{Background}

An increasing number of reports on skin involvement in patients affected with Coronavirus Disease 2019 (COVID-19) is currently available. However, very few studies on clinical-histopathological correlations of skin disorders associated with COVID-19 have been conducted [1-5]. Different clinical features of cutaneous involvement in patients affected with SARS-CoV-2 infection seem to reveal a full spectrum of viral interaction with the skin [1]. Herein, we report two COVID-19 patients developing a purpuric maculo-papular rash and a sub-erythroderma, respectively.

\section{Case presentation}

The Case 1 was a 90-year-old man, affected with hypertension and senile dementia, who tested positive for SARS$\mathrm{CoV}-2$ by reverse transcriptase-polymerase chain reaction (RT-PCR) from a nasopharyngeal swab on April 2th, 2020, after three days of fever and cough. On April 4th he was hospitalized and after eleven days transferred to Intensive Care Unit (ICU) due to the severe dyspnea, requiring intubation. A chest CT showed bilateral ground-glass opacities in upper and lower lobes. Just that day, an erythematous maculo-papular rash appeared on trunk, shoulders and neck, becoming purpuric after few days (Fig. 1a,b). On April

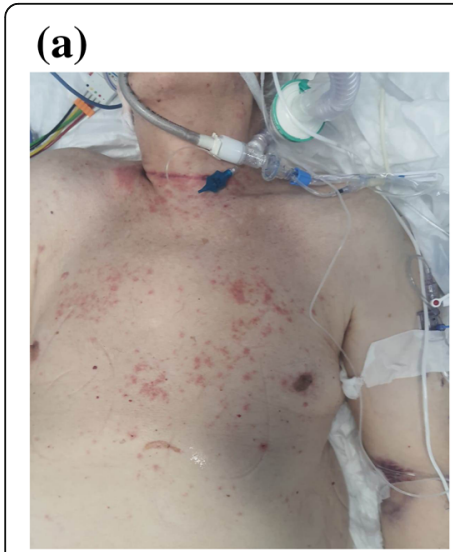

(b)
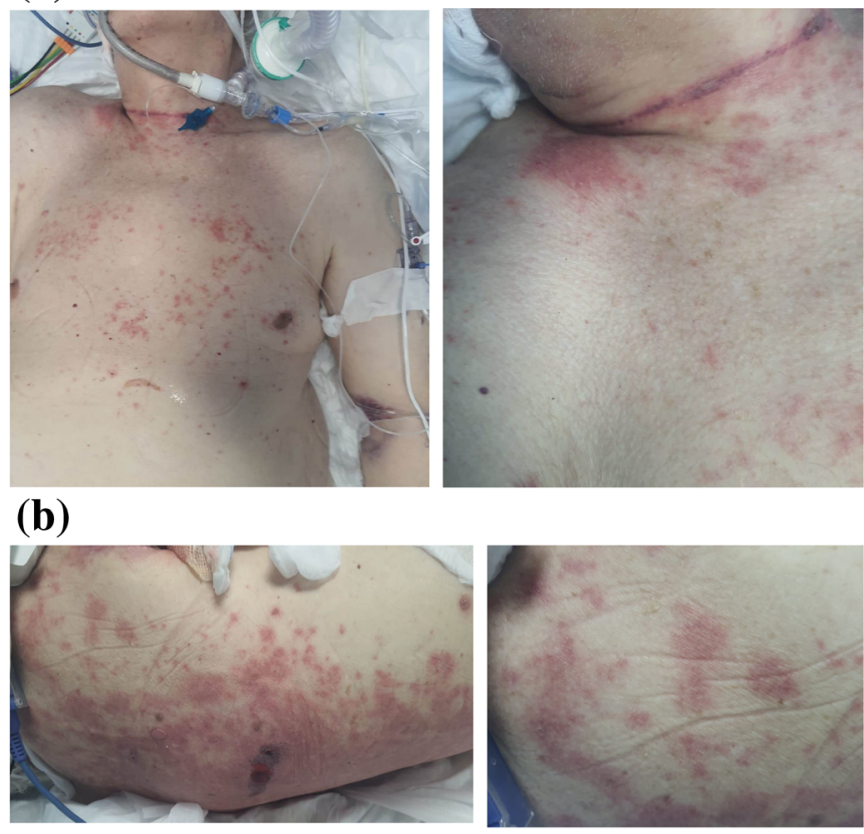

(c)

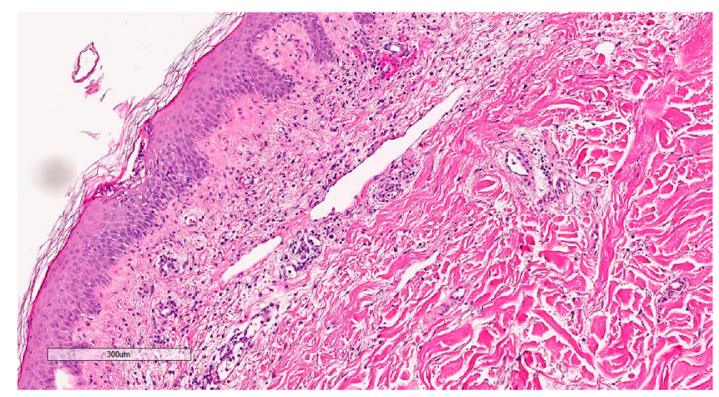

(d)

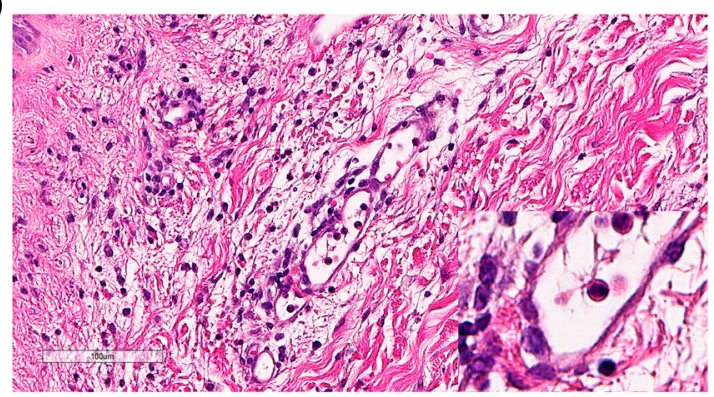

Fig. 1 a Purpuric maculo-papular rash involving trunk, neck and shoulders; b Back lesions with limited epidermal detachment; c-d The papillary and superficial dermis were edematous and populated mainly by perivascular lympho-granulocytic inflammatory infiltrate, with associated granulocyte intraepithelial exocytosis, and irregular spongiosis (blue arrow). Superficial dermal micro-areas of erythrocytic extravasation (yellow arrow) and endothelial "swelling" (green arrow in fig. $\mathbf{c}$ and fig.d; at higher magnification in inset on the right) were observed (C:H\&E, 8x; $\mathrm{D}$,H\&E, 20x, inset 40x). Legend: H\&E = hematoxylin and eosin stain 
23th, five biopsy specimens from the back and upper limbs were obtained. Histological evaluations revealed a chronic superficial dermatitis with purpuric aspects. The superficial and papillary dermis appeared edematous, with a perivascular lympho-granulocytic infiltrate and erythrocytic extravasation. At intraepithelial level, spongiosis and a granulocyte infiltrate were detected. Arterioles, capillaries and post-capillary venules showed endothelial swelling and appeared ectatic (Fig. 1c-d). The patient was treated with hydroxychloroquine, azithromycin, lopinavir-ritonavir and tocilizumab. Regrettably, due to severe lung impairment, he died on April 25th.

The Case 2 was a severely dyspneic 85 -year-old man, with a history of hypertension, cerebral vasculopathy, prostate cancer, admitted to ICU on April 19th, where he was intubated. He had tested positive for SARS-CoV-2 by RT-PCR from a nasopharyngeal swab on April 17th, after five days of fever, cough and sore throat. A chest RX showed bilateral atypical pneumonia. On April 24th, a cutaneous reddening involving trunk, upper limbs, neck and face developed, configuring progressively a suberythroderma, with mild exfoliation (Fig. 2a). After three days, four biopsy specimens were obtained. Histological evaluations displayed edema in the papillary and superficial reticular dermis, and a perivascular lymphocytic infiltrate in the superficial dermis (Fig. 2b,c). The patient was treated with hydroxychloroquine, azithromycin, lopinavirritonavir and tocilizumab. Sub-erythroderma as well as respiratory symptoms gradually improved until healing, with the hospital discharge occurring on May 5th.

\section{Discussion and conclusions}

Our first patient showed similarities with a case of purpuric rash reported by Gianotti $\mathrm{R}$ et al [1].Common histological features were lymphocytic infiltration around the swollen blood vessels with extravasated erythrocytes and spongiosis [1].Dilated vessels were also found by Zengarini $\mathrm{C}$ et al. [3] in an erythematous rash associated with COVID-19 [3].In addition to ectatic vessels, our Case 1 showed endothelial swelling. Such feature could be a morphological expression of SARS-CoV-2-induced endothelial dysfunction. Indeed, SARS-CoV-2 can infect cells by angiotensin-converting enzyme 2 receptor, largely expressed in endothelial cells [6, 7].An endotheliitis has been hypothesized as the origin of compromised microcirculation affecting lungs and kidneys in COVID-19 [7].Endothelial cells' infection could trigger activation of coagulation and diffuse microthrombosis [7].Thus, we hypothesize that cutaneous damage could be initiated by endothelial dysfunction, caused by SARS-CoV-2 infection of endothelial cells or induced by immune system activation. The disruption of endothelial integrity could enhance microvascular permeability, extravasation of inflammatory cells and cytokines, with cutaneous injury.

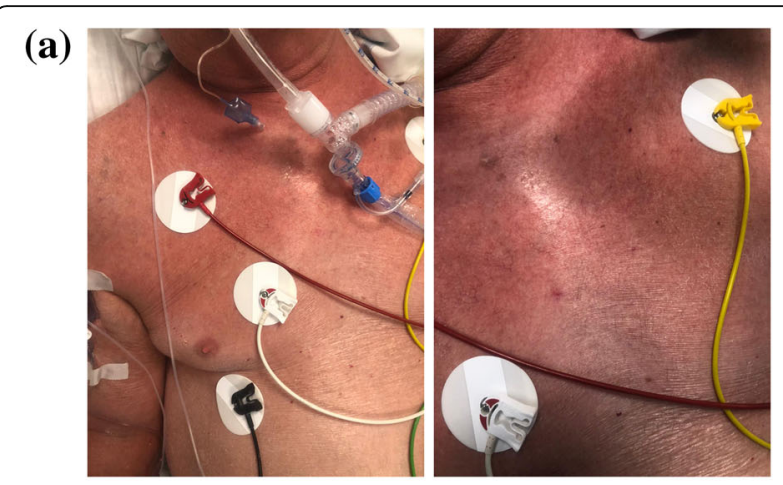

(b)

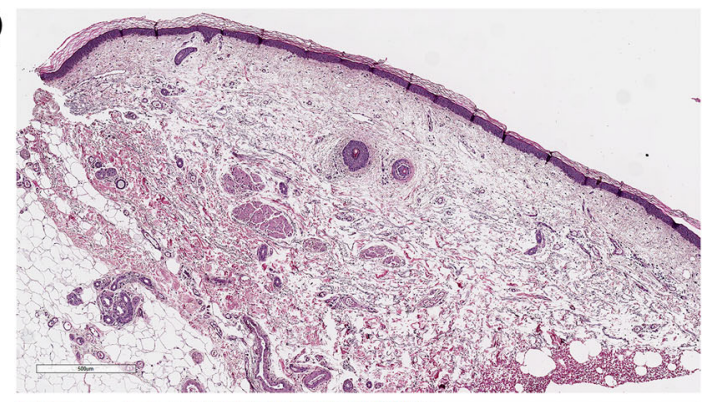

(c)

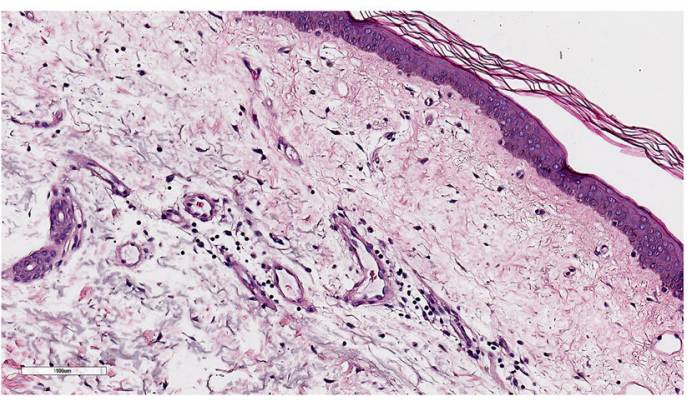

Fig. 2 a Sub-erythroderma with mild exfoliation, affecting trunk, upper limbs, neck and face; b, c Edema and moderate chronic lymphocytic inflammation, mainly perivascular, were present in the papillary and superficial reticular dermis (A:H\&E, 5x; B:H\&E, 20x)

To the best of our knowledge, our Case 2 is the first report displaying histological features of a suberythroderma associated with COVID-19. A nonspecific chronic dermatitis was detected, as often found in erythroderma from other causes. The reason why cutaneous manifestations can be so different among patients is unknown. However, it is clear that COVID-19 can lead to coagulopathy. During hospitalization, both our patients had high D-dimer levels, which were on average 3-fold higher in Case 1 in comparison with Case 2. We speculate that a purpuric rash could represent the cutaneous sign of a more severe coagulopathy, as highlighted histologically by vascular abnormalities, while a sub-erythroderma could be expression of viral hematogenous spreading, inducing a non-specific chronic dermatitis, also in absence of histopathological microangiopathy signs. 


\section{Abbreviations}

COVID-19: Coronavirus Disease 2019; RT-PCR: Reverse transcriptasepolymerase chain reaction; ICU: Intensive Care Unit

\section{Acknowledgements}

Not applicable.

\section{Authors' contributions}

(A) P. has drafted the work, has made substantial contributions to the conception of the work and analysis of data, has approved the submitted version, and has agreed both to be personally accountable for the author's own contributions and to ensure that questions related to the accuracy or integrity of any part of the work, even ones in which the author was not personally involved, are appropriately investigated, resolved, and the resolution documented in the literature: $M$. V. has made substantial contributions to the conception of the work and acquisition of the data, has approved the submitted version, and has agreed both to be personally accountable for the author's own contributions and to ensure that questions related to the accuracy or integrity of any part of the work, even ones in which the author was not personally involved, are appropriately investigated, resolved, and the resolution documented in the literature; P. (B) has made substantial contributions to the conception of the work and acquisition of the data, has approved the submitted version, and has agreed both to be personally accountable for the author's own contributions and to ensure that questions related to the accuracy or integrity of any part of the work, even ones in which the author was not personally involved, are appropriately investigated, resolved, and the resolution documented in the literature; M. (C) A. has revised the work, has approved the submitted version and has agreed both to be personally accountable for the author's own contributions and to ensure that questions related to the accuracy or integrity of any part of the work, even ones in which the author was not personally involved, are appropriately investigated, resolved, and the resolution documented in the literature; (D) R. has drafted the work, has made substantial contributions to the conception of the work, acquisition and analysis of the data, has approved the submitted version and has agreed both to be personally accountable for the author's own contributions and to ensure that questions related to the accuracy or integrity of any part of the work, even ones in which the author was not personally involved, are appropriately investigated, resolved, and the resolution documented in the literature; S. S. has revised the work, has made substantial contributions to the conception of the work, acquisition and analysis of the data, has approved the submitted version, and has agreed both to be personally accountable for the author's own contributions and to ensure that questions related to the accuracy or integrity of any part of the work, even ones in which the author was not personally involved, are appropriately investigated, resolved, and the resolution documented in the literature; G. S. has revised the work, has approved the submitted version, and have agreed both to be personally accountable for the author's own contributions and to ensure that questions related to the accuracy or integrity of any part of the work, even ones in which the author was not personally involved, are appropriately investigated, resolved, and the resolution documented in the literature; G. F. has revised the work, has made substantial contributions to the conception of the work, analysis of data, has approved the submitted version and has agreed both to be personally accountable for the author's own contributions and to ensure that questions related to the accuracy or integrity of any part of the work, even ones in which the author was not personally involved, are appropriately investigated, resolved, and the resolution documented in the literature;

\section{Funding}

none declared.

\section{Availability of data and materials}

Data sharing is not applicable to this article as no datasets were generated or analysed during the current study.

\section{Ethics approval and consent to participate}

Informed consent for the study and for the publication of the photos was obtained from the patients. The study complied with the Declaration of Helsinki.

\section{Consent for publication}

Informed consent for the study and for the publication of the photos was obtained from the patients.

\section{Competing interests}

The authors declare that they have no competing interests.

\section{Author details}

'Department of Clinical Medicine and Surgery, Section of Dermatology and Venereology, University of Naples Federico II, Via Pansini 5, Napoli, Italy. ${ }^{2}$ Department of Neurosciences, Intensive Care Unit, Reproductive and Odontostomatological Sciences, University of Naples Federico II, Via Pansini 5, Napoli, Italy. ${ }^{3}$ Department of Advanced Biomedical Sciences, Pathology Section, University of Naples Federico II, via Pansini 5, Naples, Italy.

Received: 27 July 2020 Accepted: 9 February 2021

Published online: 25 February 2021

\section{References}

1. Gianotti R, Zerbi P, Dodiuk-Gad RP. Clinical and histopathological study of skin dermatoses in patients affected by COVID-19 infection in the Northern part of Italy. J Dermatol Sci. 2020;98:141-3.

2. Diaz-Guimaraens B, Dominguez-Santas M, Suarez-Valle A, Pindado-Ortega C, Selda-Enriquez G, Bea-Ardebol S, et al. Petechial Skin Rash Associated With Severe Acute Respiratory Syndrome Coronavirus 2 Infection [published online ahead of print, 2020 Apr 30]. JAMA Dermatol. 2020;10.1001/ jamadermatol.2020.1741.

3. Zengarini C, Orioni G, Cascavilla A, Horna Solera C, Fulgaro C, Misciali C, et al. Histological pattern in Covid-19 induced viral rash [published online ahead of print, 2020 May 2]. J Eur Acad Dermatol Venereol. 2020;10.1111/ jdv.16569.

4. Jimenez-Cauhe J, Ortega-Quijano D, Carretero-Barrio I, Suarez-Valle A, Saceda-Corralo D, Moreno-Garcia Del Real C, et al. Erythema multiforme-like eruption in patients with COVID-19 infection: clinical and histological findings [published online ahead of print, 2020 May 9]. Clin Exp Dermatol. 2020;10.1111/ced.14281.

5. Robustelli Test E, Vezzoli P, Carugno A, Raponi F, Gianatti A, Rongioletti F, et al. Acute Generalized Exanthematous Pustulosis with Erythema Multiforme-Like lesions in a COVID-19 woman [published online ahead of print, 2020 May 9]. J Eur Acad Dermatol Venereol. 2020;10.1111/jdv.16613.

6. Patrì A, Gallo L, Guarino M, Fabbrocini G. Sexual transmission of severe acute respiratory syndrome coronavirus 2 (SARS-CoV-2): A new possible route of infection? J Am Acad Dermatol. 2020;82:e227.

7. Smadja DM, Guerin CL, Chocron R, Yatim N, Boussier J, Gendron N, et al. Angiopoietin-2 as a marker of endothelial activation is a good predictor factor for intensive care unit admission of COVID-19 patients [published online ahead of print, 2020 May 27]. Angiogenesis. 2020;10.1007/s10456020-09730-0.

\section{Publisher's Note}

Springer Nature remains neutral with regard to jurisdictional claims in published maps and institutional affiliations.

Ready to submit your research? Choose BMC and benefit from:

- fast, convenient online submission

- thorough peer review by experienced researchers in your field

- rapid publication on acceptance

- support for research data, including large and complex data types

- gold Open Access which fosters wider collaboration and increased citations

- maximum visibility for your research: over $100 \mathrm{M}$ website views per year

At $\mathrm{BMC}$, research is always in progress.

Learn more biomedcentral.com/submissions 